\title{
Therapeutic Option in Patients over 60 Years with Esophageal and Esocardial Cancer
}

\author{
Roșca C, Molnar C, Popa D, Serac G, Gherghinescu M, Voidazan S, Copotoiu C \\ Surgery Clinic I, County Emergency Clinical Hospital, Tîrgu Mureș, Romania
}

\begin{abstract}
Background: Treatment of esophageal and esocardial cancer in patients over 60 years involves a particular management. Considering the comorbidities specific to this category of patients, recent data from the literature indicate an increased incidence of mortality and morbidity following therapy.

Material and method: We retrospectively studied a group of 55 patients admitted to the Surgical Clinic I of the County Emergency Clinical Hospital Tîrgu Mureș, in the January 1st, 2007 - December 31st, 2011 period, diagnosed with esophageal and esocardial cancer. Patients were divided into two groups: group I under the age of 60 years, and group II over this age. Inclusion criteria were age, diagnosis (tumor location), and we followed a series of parameters: demographics, type of surgery, the biological profile of patients, immediate postoperative morbidity and mortality. Results: No statistically significant differences were observed in terms of demographics: gender $(p=0.78)$, area of origin ( $p=0.69)$. The number of hospitalization days $(p=0.20)$ was influenced by the type of surgery, as well as pre- and postoperative comorbidities. Immediate postoperative mortality was $16.56 \%$, the differences between the two groups was not statistically significant $(p=0.58)$. Parameters with statistical significance were found to be: age ( $p<0.0001)$, tumor location, type of surgery $(p=0.0031)$ and radical versus palliative surgery $(p=0.03)$. Conclusions: Therapeutic attitude in patients over 60 years should be correlated with specific particularities to this category. Selection of patients for surgery and type of surgery is dictated by the patient's condition and quantified by anesthesia and surgery team.
\end{abstract}

Keywords: esophageal,esocardial, cancer, management

Received: 11 June 2013 / Accepted: 12 February 2014

\section{Introduction}

The increasing prevalence of esophageal and esocardial cancer represents a major health problem worldwide [1,2]. Given the higher incidence of esophageal cancer in the $7^{\text {th }}$ and $8^{\text {th }}$ decade of life, the treatment of elderly patients involves a particular management due to age and associated comorbidities specific to this category of patients $[2,3,4]$.

Ellis $\mathrm{FH} \mathrm{Jr}$ et al. do not consider age a limiting factor in the aggressive management of elderly patients (aged over 70 years) [5]. Fogh et al. report no significant differences in terms of mortality and morbidity in elderly patients [6]. Moreover, Dhungel et al. considered that advanced age, along with other significant comorbidities (diabetes, stroke, peripheral vascular pathology), is a predictor of morbidity and mortality post-esophagectomy [7]. Wright et al. studied morbidity and mortality following esophagectomy on a lot of 2315 patients operated for esophageal cancer, and identified age (75 vs. 55 years), along with other comorbidities (diabetes mellitus, hypertension, smoking, coronary artery disease, etc.), as a predictor [8]. In contrast, Ruola $A$ et al. suggest that age itself should not be an exclusion criterion for esophagectomy [9].

Therapeutic options for esophageal and esocardial cancer have changed in the last 10 years [10]. The identification of risk factors, the role of surgery in the multimodal treatment of this disease, as well as the proper selection of patients [11] continue to represent challenges in choosing the proper therapeutic strategy, correlating the risk-benefit of each individual.

The objectives of our study were to evaluate the surgical options, the characteristics of immediate postoperative morbidity and mortality and the histology patterns of a group of patients diagnosed with esophageal and/or esocardial cancer.

\section{Methods}

We ran a retrospective observational study on a sample of 55 patients, hospitalized in the Surgery Clinic I of the County Emergency Clinical Hospital Tîrgu Mureș, between January $1^{\text {st }}, 2007$ - December $31^{\text {st }}, 2011$, diagnosed with esophageal and/or esocardial cancer (Siewert type I). Based on the clinical and paraclinical examination data obtained from the clinical observation sheets and postoperative protocols, patients were divided into two groups: group I under the age of 60 years, and group II over this age.

Inclusion criteria were the following:

a) Patients hospitalized in the Surgical Clinic I of the County Emergency Clinical Hospital Tîrgu Mureș in the January $1^{\text {st }}, 2007$ - December $31^{\text {st }}, 2011$ period;

b) Adult age (over 18 years);

c) Admission diagnosis confirmed (esophageal cancer and/or esocardial Siewert type I).

Exclusion criteria were:

a) patients hospitalized with esophageal or esocardial cancer, who were not operated; 
Table I. General characteristics

\begin{tabular}{|c|c|c|c|}
\hline & $\begin{array}{l}\text { Lot I }(n=23) \\
<60 \text { years }\end{array}$ & $\begin{array}{l}\text { Lot II }(n=32) \\
>60 \text { years }\end{array}$ & $p$ value \\
\hline Age & $54 \pm 4.9$ & $68.8 \pm 5.7$ & $<0.0001^{\star}$ \\
\hline \multicolumn{4}{|l|}{ Sex } \\
\hline Male & 20 (86.96\%) & 27 (84.38\%) & \\
\hline Female & $3(13.04 \%)$ & $5(15.63 \%)$ & \\
\hline $\begin{array}{l}\text { Overall mortality }(16.56 \% \\
\text { from } n=55)\end{array}$ & $5(21.74 \%)$ & $4(12.50 \%)$ & $0.58^{\star \star}$ \\
\hline BMI & $21.7 \pm 3.9$ & $22.9 \pm 3.7$ & $0.2^{\star}$ \\
\hline \multicolumn{4}{|l|}{ Demographic data } \\
\hline Urban & $8(34.78 \%)$ & $14(43.75 \%)$ & $0.69^{\star \star}$ \\
\hline Rural & $15(78.26 \%)$ & 18 (56.25\%) & \\
\hline No. of days of hospitalization & $21(7-52)$ & $15(7-41)$ & $0.20^{\star \star \star}$ \\
\hline No. of days of ICU & $6(1-13)$ & $8(1-32)$ & $0.5^{\star \star \star}$ \\
\hline Onset of symptoms (weeks) & $12(1-24)$ & $8(1-40)$ & $0.51^{\star \star \star}$ \\
\hline $\begin{array}{l}\text { Presence of dysphagia } \\
\text { (dominant symptom) }\end{array}$ & $16(69.57 \%)$ & $22(68.75 \%)$ & $0.8^{\star \star \star \star}$ \\
\hline Major comorbidities & $10(43.48 \%)$ & $24(75 \%)$ & $0.03^{\star \star \star \star}$ \\
\hline Postoperative morbidity & $5(21.74 \%)$ & $17(53.13 \%)$ & $0.038^{\star \star \star \star}$ \\
\hline
\end{tabular}

${ }^{*}$ t Student test, ${ }^{* \star}$ chi2 test, ${ }^{* \star \star}$ Mann-Whitney test, ${ }^{\star \star \star \star}$ comparison of proportions

b) patients with benign tumors;

c) patients with postcaustic stenosis;

d) patients under the age of 18 years.

Statistical analysis was performed using MedCalc Software (Version 12.3.0 bvba, Mariakerke, Belgium). Student's $t$ test was used to assess the differences in continuous variables (expressed as mean $\pm \mathrm{SD}$ ) and Mann Whitney test for nonparametric variables (expressed as median and range) while the $\chi^{2}$ test was used for category variables (expressed as no (\%). We interpreted all the tests we have performed to the threshold of significance $p=0.05$ and statistical significance was considered for $\mathrm{p}$-values less than the threshold value of significance.

\section{Results}

On the studied groups, no statistically significant differences were observed regarding sex. Males were predominantly affected $(86.86 \%$ and $84.38 \%)$ (Table I). Overall mortality was $16.56 \%$ without obvious difference between the two groups (Table I). There was no difference between the mean values of BMI $(p=0.2)$. There was no evidence of significant difference in the area of origin, with rural area of origin being predominant $(78.26 \%$ and $56.25 \%)$.

Table II. Type of surgery

\begin{tabular}{lccc}
\hline Type of surgery & $\begin{array}{c}\text { Lot I }(\mathrm{n}=23) \\
<60 \text { years }\end{array}$ & $\begin{array}{c}\text { Lot II }(\mathrm{n}=32) \\
>60 \text { years }\end{array}$ & p value \\
\hline $\begin{array}{l}\text { With radical intent } \\
\text { Double cervical-abdominal } \\
\text { approach }\end{array}$ & $9(39.13 \%)$ & $5(15.63 \%)$ & \\
$\begin{array}{l}\text { Double thoraco-abdominal } \\
\text { approach }\end{array}$ & $3(13.04 \%)$ & $4(12.50 \%)$ & \\
$\begin{array}{l}\text { Triple approach } \\
\text { Palliative }\end{array}$ & $1(4.35 \%)$ & $1(3.13 \%)$ & $\mathrm{p}=0.03$ \\
$\quad$ Jejunostomy & & & $\left(\mathrm{chi}^{2}\right)$ \\
$\quad \begin{array}{l}\text { Gastrostomy } \\
\text { Exploratory laparotomy }\end{array}$ & $5(21.74 \%)$ & $14(43.75 \%)$ & \\
\hline
\end{tabular}

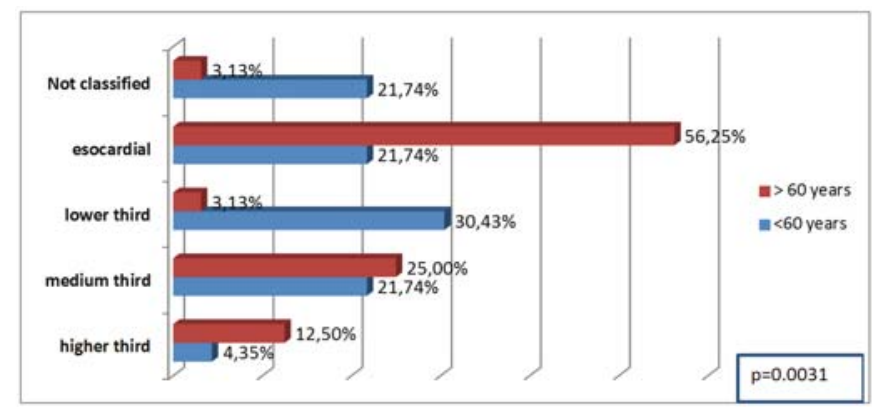

Fig. 1. Location of esophageal and esocardial cancer

Regarding the number of days of hospitalization and number of days in the ICU, the differences were not statistically significant in the studied groups, although the group over 60 years the number of days of hospitalization in the ICU was slightly higher. The onset of symptoms, between 8-12 months, was characteristic of both groups, as well as the presence of dysphagia as a dominant symptom. Both major comorbidities (diabetes mellitus, history of stroke, heart disease, lung disease) and postoperative morbidity (suppurations the wound, respiratory problems, anastomosis fistula, difficulty in resuming alimentation) presented statistically significant differences in the studied groups (Table I).

In the group over 60 years the tumor was predominantly located esocardially and in the middle third of the esophagus ( $56.25 \%$ and $25 \%$, respectively), compared to the group under 60 years where the predominant location was in the lower third (30.43\%), the difference being statistically significant $(\mathrm{p}=0.0031)$ (Figure 1$)$.

In the group over 60 years, palliative interventions dominated the therapeutic intent, there was a statistically significant difference regarding surgical management of the two groups (Table II).

Regarding the histological characteristics of the tumors and $\mathrm{T}$ and $\mathrm{N}$ classification, there were no statistically significant differences noted between the two groups (Table III).

Table III. Tumor characteristics of esophageal and esocardial cancer

\begin{tabular}{lccc}
\hline Tumor characteristics & $\begin{array}{c}\text { Lot I }(\mathrm{n}=23) \\
<60 \text { years }\end{array}$ & $\begin{array}{c}\text { Lot II }(\mathrm{n}=32) \\
>60 \text { years }\end{array}$ & p value \\
\hline Adenocarcinoma & $7(30.43 \%)$ & $15(46.88 \%)$ & 0.3 \\
Carcinoma & $16(69.57 \%)$ & $17(53.13 \%)$ & 0.3 \\
T1b & 0 & $1(3.13 \%)$ & 0.8 \\
T2 & $7(30.43 \%)$ & $4(12.50 \%)$ & 0.19 \\
T3 & $11(47.83 \%)$ & $18(56.23 \%)$ & 0.73 \\
T4a & $3(13.04 \%)$ & $5(15.63 \%)$ & 0.9 \\
T4b & $2(8.70 \%)$ & $4(12.50 \%)$ & 0.9 \\
N0 & $4(17.39 \%)$ & $3(9.38 \%)$ & 0.6 \\
N1 & $11(47.83 \%)$ & $17(53.13 \%)$ & 0.9 \\
N2 & $6(26.09 \%)$ & $7(21.88 \%)$ & 0.9 \\
N3 & $2(8.70 \%)$ & $5(15.63 \%)$ & 0.7 \\
\hline
\end{tabular}

* comparison of proportions 
Table IV. Type of surgery: radical vs. palliative

\begin{tabular}{lcccc}
\hline Type of intervention & \multicolumn{2}{c}{$\begin{array}{c}\text { Lot I }(\mathrm{n}=23) \\
<60 \text { years }\end{array}$} & \multicolumn{2}{c}{$\begin{array}{c}\text { Lot II }(\mathrm{n}=32) \\
>60 \text { years }\end{array}$} \\
\cline { 2 - 5 } & $\mathrm{n}$ & $\%$ & $\mathrm{n}$ & $\%$ \\
\hline Radical & 13 & $56.52 \%$ & 10 & $31.25 \%$ \\
Palliative & 10 & $43.48 \%$ & 22 & $68.75 \%$ \\
\hline
\end{tabular}

\section{Discussion}

Therapeutic options with acceptable radical intention in front of a patient with esophageal and/or esogastric (Siewert type I) cancer are in accordance with age-specific comorbidities [12]. Palliative interventions predominated in the age group over 60 years $(68.75 \%)$, while in the group under 60 years radical interventions represented the first intention (56.52\%) (Table IV).

Our results suggest that tumor characteristics (histologic type) do not influence the therapeutic decision, radical intent being primordial in the case of patients with esophageal cancer.

We found that the tumors were located more commonly in the distal third of the esophagus in group II, while in group I they were located predominantly in the middle third $(81.25 \%$ and $52.17 \%, \mathrm{p}=0.0031)$, similarly to the findings of Dreilich $\mathrm{M}$ et al. [13]. Full evaluation of preoperative comorbidities is essential in choosing the type of surgery, considering the anesthetic risk correlated with postoperative evolution [14].

Comorbidities (cardio-pulmonary, diabetes, etc.) were more common in group II, which influence the type of intervention, representing contraindication to extensive surgery in the chest and performing a minimum surgical act (jejunostomy, gastrostomy).

Postoperative evolution of patients is influenced to a greater extent by the existence of comorbidities, while immediate postoperative mortality is not higher following radical surgery, compared with palliative surgery.

\section{Conclusions}

Our results suggest that age, as a singular criterion, should not be an impediment in the selection of patients for a radical intervention.
Surgical interventions for esophageal cancer and esocardial are the prerogative of experienced surgical and anesthetic teams, preoperative and postoperative care is often as important as the type of surgical procedure chosen.

\section{References}

1. Ajani JA, Barthel JS, Bekaii-Saab T, et al. NCCN Esophageal Cancer Panel-Esophageal cancer. J Natl Compr Canc Netw. 2008;6(9):818-49.

2. McLoughlin JM, Lewis JM, Meredith $\mathrm{KL}$. The impact of age on morbidity and mortality following esophagectomy for esophageal cancer. Cancer Control. 2013;20(2):144-50.

3. Pérez Pereyra J, Frisancho Velarde O. Esophageal cancer: epidemiological, clinical, and pathological characteristics at Hospital Rebagliati (Lima). Rev Gastroenterol Peru. 2009;29(2):118-23.

4. Fang $W$, Igaki $H$, Tachimori $Y$, et al. Three-field lymph node dissection for esophageal cancer in elderly patients over 70 years of age. Ann Thorac Surg. 2001;72(3):867-871.

5. Ellis FH Jr, Williamson WA, Heatley GJ. Cancer of the esophagus and cardia: does age influence treatment selection and surgical outcomes? J Am Coll Surg. 1998;187(4):345-51.

6. Fogh SE, Yu A, Kubicek GJ, et al. Do elderly patients experience increased perioperative or postoperative morbidity or mortality when given neoadjuvant chemoradiation before esophagectomy? Int J Radiat Oncol Biol Phys. 2011;80(5):1372-6. doi: 10.1016/j.jirobp.2010.04.055.

7. Dhungel B, Diggs BS, Hunter JG, et al. Patient and peri-operative predictors of morbidity and mortality after esophagectomy: American College of Surgeons National Surgical Quality Improvement Program (ACS-NSQIP), 2005-2008. J Gastrointest Surg. 2010;14(10):1492-501. doi: 10.1007/s11605-010-1328-2.

8. Wright CD, Kucharczuk JC, O'Brien SM, Grab JD, Allen MS. Society of Thoracic Surgeons General Thoracic Surgery Database-Predictors of major morbidity and mortality after esophagectomy for esophageal cancer: a Society of Thoracic Surgeons General Thoracic Surgery Database risk adjustment model. J Thorac Cardiovasc Surg. 2009;137(3):587-95; discussion 596. doi: 10.1016/j.jtcvs.2008.11.042. Erratum in: J Thorac Cardiovasc Surg. 2009 Jun;137(6):1581.

9. Ruol A, Portale G, Zaninotto G, et al. Results of esophagectomy for esophageal cancer in elderly patients: age has little influence on outcome and survival. J Thorac Cardiovasc Surg. 2007;133(5):1186-92.

10. Wolf MC, Zehentmayr F, Schmidt M, Hölzel D, Belka C. Treatment strategies for oesophageal cancer - time-trends and long term outcome data from a large tertiary referral centre. Radiat Oncol. 2012;7:60. doi: 10.1186/1748-717X-7-60

11. Wolf MC, Stahl M, Krause BJ, et al. Curative treatment of oesophageal carcinoma: current options and future developments. Radiat Oncol. 2011; 6:55. doi: 10.1186/1748-717X-6-55

12. National Comprehensive Cancer Network Guidelines, Inc. 2013, Version 2.2013, 06.06.2013

13. Dreilich M, Bergström S, Wagenius G, Brattström D, Bergqvist M. A retrospective study focusing on clinical predictive factors in 126 patients with oesophageal carcinoma. Anticancer Res. 2004;24(3b):1915-20.

14. Löhlein D. Esophageal carcinoma: surgical treatment concepts; access and resectability. Schweiz Med Wochenschr. 1999;129(34):1211-6. 